\title{
Author Correction: How to probe the spin contribution to momentum relaxation in topological insulators
}

Moon-Sun Nam¹, Benjamin H. Williams (10 1, Yulin Chen¹, Sonia Contera1, Shuhua Yao², Minghui Lu (i) ${ }^{2}$, Yan-Feng Chen ${ }^{2}$, Grigore A. Timco ${ }^{3}$, Christopher A. Muryn ${ }^{3}$, Richard E.P. Winpenny (D) ${ }^{3}$ \& Arzhang Ardavan (D) ${ }^{1}$

Correction to: Nature Communications(2017) https://doi.org/10.1038/s41467-017-02420-4, published online 04 January 2018

The original version of this Article contained an error in the spelling of the author Benjamin H. Williams, which was incorrectly given as Benjamin H. Willams. This has now been corrected in both the PDF and HTML versions of the Article.

Published online: 15 February 2018

\begin{abstract}
(c) (i) Open Access This article is licensed under a Creative Commons Attribution 4.0 International License, which permits use, sharing, adaptation, distribution and reproduction in any medium or format, as long as you give appropriate credit to the original author(s) and the source, provide a link to the Creative Commons license, and indicate if changes were made. The images or other third party material in this article are included in the article's Creative Commons license, unless indicated otherwise in a credit line to the material. If material is not included in the article's Creative Commons license and your intended use is not permitted by statutory regulation or exceeds the permitted use, you will need to obtain permission directly from the copyright holder. To view a copy of this license, visit http://creativecommons.org/licenses/by/4.0/.
\end{abstract}

(C) The Author(s) 2018

\footnotetext{
${ }^{1}$ The Clarendon Laboratory, Department of Physics, University of Oxford, OX1 3PU Oxford, UK. ${ }^{2}$ National Laboratory of Solid State Microstructures \& Department of Materials Science and Engineering, Nanjing University, 210093 Nanjing, China. ${ }^{3}$ School of Chemistry and Photon Science Institute, The University of Manchester, M13 9PL Manchester, UK Correspondence and requests for materials should be addressed to

M.-S.N. (email: moon-sun.nam@physics.ox.ac.uk) or to A.A. (email: arzhang.ardavan@physics.ox.ac.uk)
} 